\title{
Repair of The Bracket and Clutch Mechanism On Centrifugal Pump For Firefighter Motorcycle
}

\author{
Triyono $^{1,}$, Himawan Hadi Sutrisno ${ }^{1, *}$ \\ ${ }^{1}$ Fire Safety Engineering Department, Universitas Negeri Jakarta, Indonesia
}

\begin{abstract}
An addition of centrifugal pump on the engine of automatic motorcycles is expected to become one of the solutions for fire incidents in densely populated areas in big cities. Many cases of fire-related incidents have not been handled properly due to limitations of access for fire engines such as narrow alleys. The effectiveness of the centrifugal pump for firefighter motorcycles is determined by the optimum function of the pump performance according to the desired specification. The repair of the brackets and the clutch mechanism for the pump in the engine of automatic motorcycles may assist to the full effectiveness of the pump. The repair is based on the stability of the number of cycle on the centrifugal pump during the cycle of the motorcycle engine without any load. There is no disruption to the motorcycle cruise control or an increase of load due to the addition of centrifugal pump in the motorcycle's engine. By using the magnetic clutch which uses the electrical energy in the connection and disconnection of the joint, this model will be useful since it does not disrupt the motorcycle cruise performance and does not add an extra load to the motorcycle torso.
\end{abstract}

\section{Introduction}

Densely populated areas that are commonly found in big cities such as Jakarta are the areas in which the incidents of fire are the highest. The most common causes of these fire incidents are short circuits, followed by gas cylinder explosions. Based on the data released by the fire department office in Jakarta, the incidents of fire from January to July 2017 can be seen in the graph as shown in Fugure 1.

From the reference above, that 28-78 fire incidents happened in Jakarta last year and $90 \%$ occurred in houses located in densely populated areas. One difficulty that the fire department has to deal with in the cases of fire occurred in densely populated areas is that the fire trucks have limited accesses to the fire location. By adding a centrifugal pump to the motorcycle engine, the firefighter motorcycle is then created and hoped to become one of the applicable solutions to the fire in urban areas [1]. Although the capacity of the centrifugal pump in a motorcycle is still far below the capacity of the centrifugal pump of a fire truck, the dimension of the motorcycle becomes an advantage in the city's narrow alleys. Motorcycles are also easy to ride and maneuver.

* Corresponding author :himawansutrisno@yahoo.com 


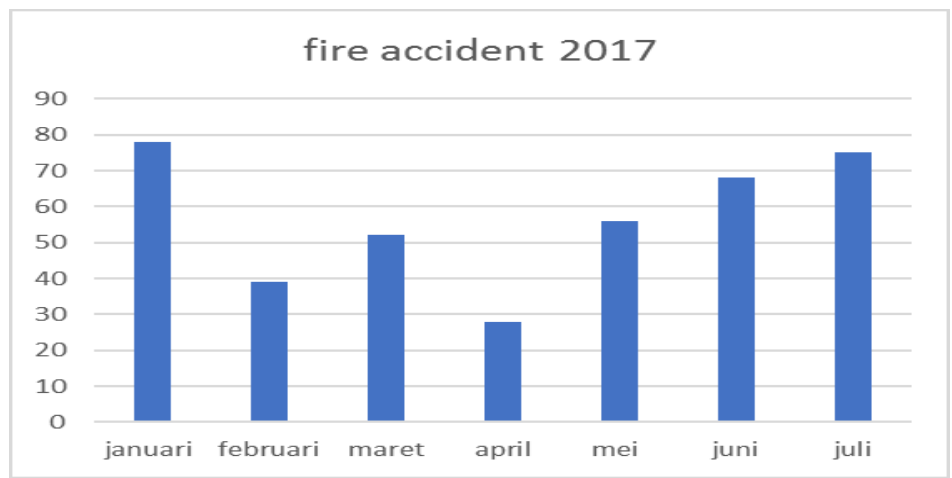

Fig. 1. The Number of Fire Incidents over the period of January - July in Jakarta

The previous research on firefighter motorcycles discusses the installation of the centrifugal pump in the motorcycle by using the manual clutch connected to the axis in the continuously variable transmission (CVT) component of an automatic motorcycle. Therefore, since the cycle of the centrifugal pump follows the CVT cycle in the engine, it is difficult to maintain stability[2]. This burdens the engine when the motorcycle is ridden to the fire location. The use of a magnetic clutch and the improvement in the mechanism of the centrifugal pump are hoped to improve the firefighter motorcycle's performance. The repair of brackets and magnetic clutch mechanism are explained in the sub-chapters below.

\section{Related Works}

The increase in the number of houses in urban areas has contributed to the development of densely populated areas in certain areas [3]. The growth of population is proportionate to the increase of energy consumption [4] which results in the increase of fire incidents in the urban areas [5]. Although one solution to this issue which is vertical housing such as apartments and flats has been provided by the government, without a comprehensive solution to the fire incidents, the vertical housing remains high for fire risks [6]. The efforts to prevent fire in the residential areas are influenced by the social conditions of the community and the index living condition (ILC). This was mentioned by Niklas Guldaker [7] for the Malmo Sweden study case. Lopes and Hao [8, 9] state that the mitigation of fire is a joint effort between the community and the government as the decision-maker for public policies.

To prevent the loss of lives and materials due to fire in densely populated areas, city planning must be done well $[10,11]$. This may be done by adding evacuation routes or maps in case of fire as explained by Dian who discusses the fire in densely populated areas in Surabaya. This also applies to public areas such as campuses where students must be aware of the correct locations of the fire equipment and the evacuation routes during fire.

Aside from the social and cultural conditions of the community, the equipment also become a determining factor in the success of the prevention and mitigation of fire [12]. Efforts have been made for the past several years to develop an early detection of fire [13] which allows a quick response for the community during fire. Other means such as the development of fire prevention equipment [14], fire resistant materials [15], until the evolution of the fire trucks [16] have also been developed by researchers. However, all these means are not applicable to certain areas such as densely populated areas since they have not solved the issue of limited access to the areas. One example of problems that need 
to be solved is the narrow alleys that are not accessible by fire trucks. Therefore, a firefighting equipment that can be used in narrow alleys needs to be specially designed.

\section{Research Method}

In the beginning, the firefighter motorcycles that have been found in the market use the motorcycle's fuel to move the centrifugal pump. Since this kind of setting requires the motorcycle to provide extra spaces for the centrifugal pump, fuel, and other firefighting equipment, the dimension of the motorcycle becomes larger. In its development, the centrifugal pump in the firefighter motorcycle may be installed in the CVT of the motorcycle using the bracket as the clutch for the centrifugal pump. This, however, creates a complication in the operation. The number of cycle in the centrifugal pump and the volume of water sprayed remains unstable. Therefore, to increase the effectiveness of the centrifugal pump in the firefighter motorcycle, research was conducted, and the flow chart of the research can be seen below:

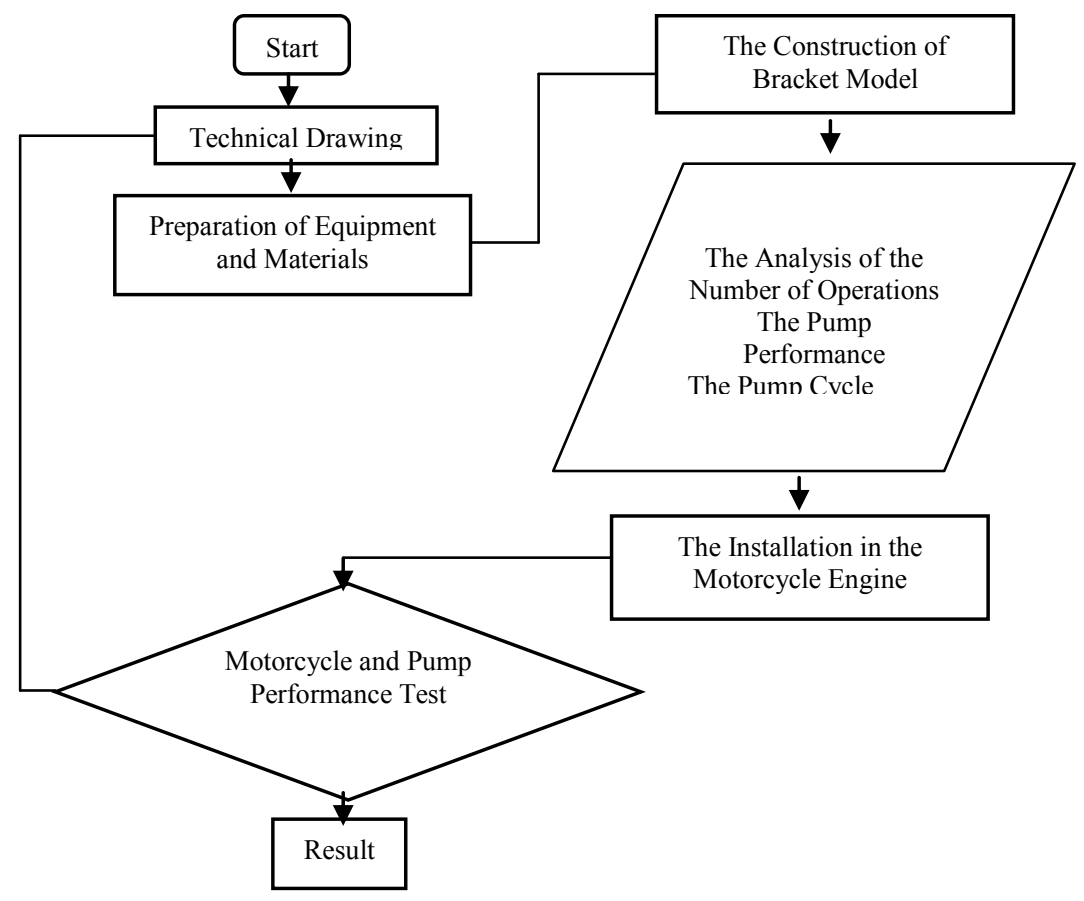

Fig. 2. Flow chart of the Research Procedure

The flow chart shows that the research started from assessing the installment of bracket from the previous research, the installment of the bracket, the tightening of the centrifugal pump, and the calculation of the new dimension after the installment of the pump in the motorcycle. The analysis of the bracket repair was based on the performance of the centrifugal pump in the motorcycle. The result of this research was a model which had passed the test for the performance of the centrifugal pump in the firefighter motorcycle. 


\section{Repair for Bracket and Clutch Mechanism in the Centrifugal Pump}

The equipment used in the firefighter motorcycle can be seen in Table 1 below. The main component of the equipment is the centrifugal pump to spray the water. The volume of the water and the pressure produced by the centrifugal pump must be taken into account carefully in order to avoid adding an extra load to the motorcycle.

Table 1. The Firefighter motorcycle components[1]

\begin{tabular}{|l|l|l|}
\hline No & Description & Specification \\
\hline 1 & Centrifugal pump & $2.2 \mathrm{KW}$ \\
\hline 2 & Bracket Pump & Custom, hand made \\
\hline 3 & Rubber hose bracket & Custom, hand made \\
\hline 4 & Rubber hose outlet & 2 inch, length $20 \mathrm{~m}$ \\
\hline 5 & Suction hose & 2 inch, length $20 \mathrm{~m}$ \\
\hline 6 & Store box & Capacity 20 liters \\
\hline 7 & Siren lamp & \\
\hline
\end{tabular}

Also, the bracket must be designed according to the specification of the centrifugal pump used. Table 2 shows the specification of the centrifugal pump used:

Table 2. The Specification for the Centrifugal Pump[1]

\begin{tabular}{|l|l|l|}
\hline no & Description & Specification \\
\hline 1 & Power & $2.2 \mathrm{KW}$ \\
\hline 2 & Dimension & $\mathrm{H} 240 \times \mathrm{W} \mathrm{W} 198 \times \mathrm{D} 132 \mathrm{~mm}$ \\
\hline 3 & Weigh & $4.8 \mathrm{~kg}$ \\
\hline 4 & Body material & Cast iron \\
\hline
\end{tabular}

In the installation of the centrifugal pump, the bracket is used to support the body of the pump and to attach it to the engine which it uses as the main power. For the clutch component, the magnetic model is chosen since its electrical power is used to connect the magnet component. This model is used in many centrifugal pumps and has been patented by Kiker, et al. For the firefighter motorcycle, the Magnetic clutch Type $\mathrm{g}$ is used which can be seen below:

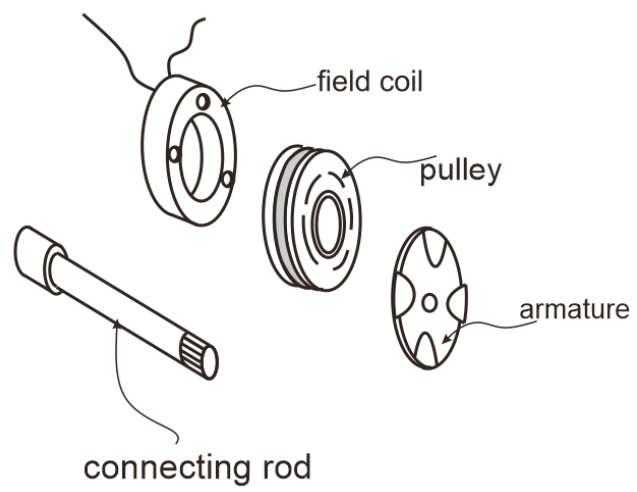

Fig. 3. Magnetic Clutch Type g

From the shape of the clutch seen above, it can be seen that the bracket for the pump is adjusted so that it could be placed next to the clutch and connected with a belt with a 
pulley placed on the centrifugal pump. The pulley in the centrifugal pump and the pulley in the magnetic clutch have a ratio of 1: 2 or this means that 1 cycle of the pulley in the magnetic clutch creates 2 cycles in the pump. The ratio refers to the cycle of the centrifugal pump used which is the $1450 \mathrm{rpm}$. Meanwhile, the cycle of the automatic motorcycle engine at a stationary position is $700 \mathrm{rpm}$. The construction of the bracket for the centrifugal pump is as follows:

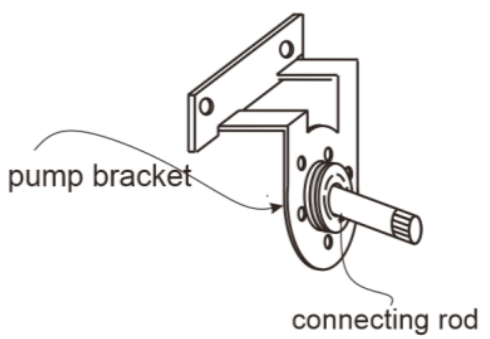

Fig. 4. The Construction of the Bracket in the Centrifugal Pump

Meanwhile, the installment of the pump with the pulley for the firefighter motorcycle is as follows:

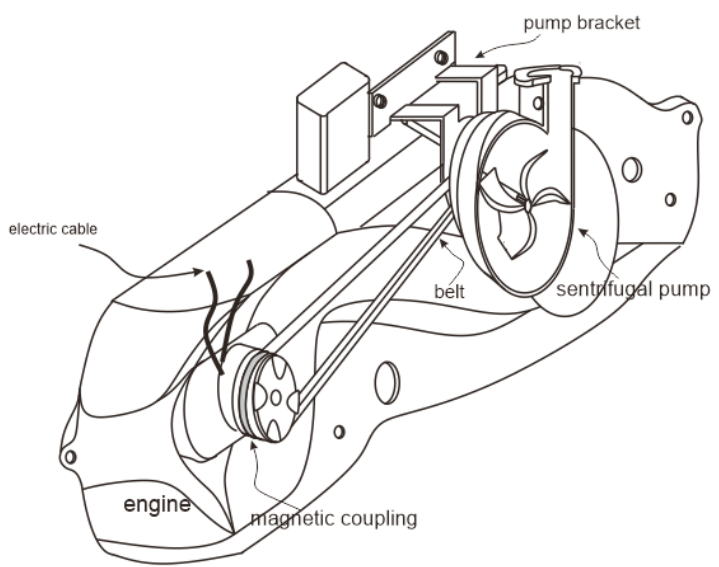

Fig. 5. The Installation of Centrifugal Pump in the Firefighter Motorcycle.

The repair and the improvement that are done can be seen in Table 3 below:

Table 3. The comparison old design and new design of bracket firefighter motorcycle

\begin{tabular}{|l|l|l|l|}
\hline No & Items of Repair & Old Design & New Design \\
\hline 1 & The number of cycles & $\begin{array}{l}\text { depending on engine } \\
\text { rotation }\end{array}$ & $\begin{array}{l}\text { 700 rpm on the engine } \\
\text { equal with 1400 rpm } \\
\text { on the centrifugal } \\
\text { pump }\end{array}$ \\
\hline 2 & The stability of the cycles & Not stabil & stabil \\
\hline 3 & $\begin{array}{l}\text { The total width of the } \\
\text { installed pump }\end{array}$ & $750 \mathrm{~mm}$ & $820 \mathrm{~mm}$ \\
\hline 4 & $\begin{array}{l}\text { Construction of centrifugal } \\
\text { pump }\end{array}$ & Coupled with CVT & $\begin{array}{l}\text { Pulley and belt ratio } \\
2: 1\end{array}$ \\
\hline 5 & The number of spare parts & 5 part & 8 part \\
\hline
\end{tabular}

The following is the illustration of the water volume test in the firefighter motorcycle after the repair and the improvement. 


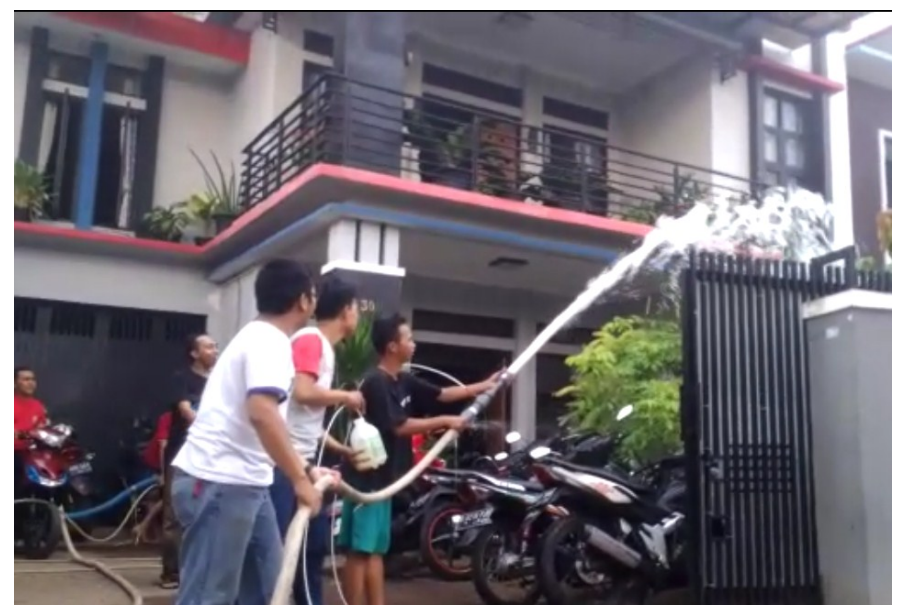

Fig. 6. The Illustration for the Centrifugal Pump Test

\section{Discussion and Conclusion}

Although the repair of the brackets and the improvement of the clutch mechanism resulted in few modifications such as an addition to the motorcycle part, which is the belt component, and the shift of the centrifugal pump location due to the reduction of cycle used to reach the 1400 cycles during the normal cycle of the engine, there was no increase to the motorcycle load. This is because the magnetic clutch is not needed during cruise time. In the cycle of the centrifugal pump, when the engine is in a low cycle position (700rpm), the pulley and belt mechanism may be used with a 1:2 ratio. The following is the result of the initial trial using the repair of the brackets and the magnetic clutch mechanism in the firefighter motorcycle.

Table 4 the comparison of preliminary reseach of improve firefighter motor cycle bracket

\begin{tabular}{|l|l|l|l|}
\hline No & Item test & Old design & New design \\
\hline 1 & $\begin{array}{l}\text { The stability of } \\
\text { water outlet }\end{array}$ & $\begin{array}{l}\text { depending on engine } \\
\text { rotation }\end{array}$ & $\begin{array}{l}\text { Stabil in the low and } \\
\text { hight rotation }\end{array}$ \\
\hline 2 & The water pressure & $\begin{array}{l}1.69 \text { bar in the 2000 } \\
\text { rpm }\end{array}$ & $\begin{array}{l}1.39 \text { Bar in the 700 } \\
\text { rpm (low rotation) }\end{array}$ \\
\hline 3 & $\begin{array}{l}\text { The maximum } \\
\text { height of the water } \\
\text { spray }\end{array}$ & 4.1. meter \\
\hline
\end{tabular}

The table above shows that the repair of brackets and the improvement of the clutch mechanism increased the effectiveness of the firefighter motorcycle. The repair and the improvement resulted in an increase effective mechanism of centrifugal pump coupling. With this model, the firefighter motorcycles will no longer have an additional burden at cruise time.

\section{References}

1. H. H. Sutrisno and Triyono, "Designing a Firefighter Motorcycle as an Effort to Provide an Early Response to Fire Disaster," Journal of Mechanical Engineering vol. SI 4, p. 13, 2017. 
2. S. Himawan Hadi, "The selection of flying roller as an effort to increase the power of scooter-matic as the main power of centrifugal pump for fire fighter motor cycle," IOP Conference Series: Materials Science and Engineering, vol. 324, p. 012055, 2018.

3. S. Ahmed, "Assessment of urban heat island and impact of climate change on socioeconomic over Suez Governorate using remote sensing and GIS techniques," The Egyptian Journal of Remote Sensing and Space Science, vol. 21, p. 11, 2018.

4. E. Resch, R. A. Bohne, T. Kvamsdal, and J. Lohne, "Impact of urban density and building height on energy use in cities," Energy Procedia, vol. 96, p. 15, 2016.

5. A. Jonsson, C. Bonander, F. Nilson, and F. Huss, "The State of the residential fire fatality problem in sweden; Epidemiology, risk factor, and event typologies," Journal of Safety Research, vol. 52, p. 12, 2017.

6. J. LIU and W. K. CHOW, "Determination of fire load and heat release rate for highrise residential buildings," Procedia Engineering, vol. 84, p. 7, 2014.

7. N. Guldaker and P.-o. Halim, "Spatio-temporal patterns of intentional fires, social stress and socio-economic determinants: A case study of Malmo, Sweden," Fire Safety Journal, vol. 70, p. 10, 2014.

8. Y. Hao-wei, "Development of Fire Science and Fire Protection Engineering in China," Procedia Engineering, vol. 52, p. 2, 2013.

9. S. Lopez-Aparicio, M. Vogt, P. Schneider, M. Kahila-Tani, and A. Broberg, "Public participation GIS for improving wood burning emission from residential haeting and urban environmental management," Journal of Environmental Management, vol. 191, p. 10, 2017.

10. E. K. Addai, S. K. Tulashie, J.-S. Annan, and I. Yeboah, "Trend of Fire Outbreaks in Ghana and Ways to Prevent These Incidents," Safety and Health at Work, vol. 7, p. 9, 2016.

11. A. R. Harper, S. H. Doerr, C. Santin, C. A. Froyd, and P. Sinnadurai, "Prescribed fire and its impacts on ecosystem service in the UK," Science of the Total Environment, vol. 624, p. 13, 2018.

12. R. Kuffel, P. Forsyth, and C. Peters, "The Role and Importance of Real Time Digital Simulation in the Development and Testing of Power System Control and Protection Equipment," IFAC Paper Online, vol. 49, p. 5, 2016.

13. L. Giglio, W. Schroeder, and C. O. Jusctice, "The collection 6 MODIS active fire detection algorithm and fire products," Remote Sensing of Environment, vol. 178, p. 11, 2016.

14. C.-p. WANG and B.-j. SHIH, "Research on the Integration of Fire Water Supply," Procedia Engineering, vol. 211, p. 10, 2018.

15. K. Mroz, I. Hager, and K. Korniejenko, "Material solution for passive fire protection of building and structures and their performances testing," Procedia Engineering, vol. 151, p. 8, 2016.

16. W. Ge, J. Yong-xing, and S. Yao-zong, "The 3rd Generation Fire Truck and its Spraying Technique," procedia Engineering, vol. 11, p. 7, 2011. 